\title{
Plagiarism and How to Avoid it
}

Mochammad Tanzil Multazam, M.Kn.

Head of Sciemtific Publication Center

Universitas Muhammadiyalh Sidoarjo

(lhttps:/lorcid.org/0000-0002-6373-II99) 
"...the consequences of plagiarism are much more seric
than the consequences of turning in a paper late..." Harvard Guide to Using Sources

http://isites.harvard.edu/icb/icb.do?keyword=k70847\&p d=icb.page 342057 


\section{Plagiasi}

- perbuatan secara sengaja atau tidak sengaja dalam memperoleh atau mencoba memperoleh kredit atau r untuk suatu karya ilmiah, dengan mengutip sebagia atau seluruh karya ilmiah pihak lain yang diakui sebagai karya ilmiahnya, tanpa menyatakan sumbe secara tepat dan memadai.

"Permendiknas Nomor I7 Tahun 20 I0. Pasal I" 


\section{Jenis Plagiasi (Permendiknas)}

a.mengutip istilah, kata-kata dan/atau kalimat, data dan/atau informa tanpa menyatakan sumber secara memadai;

b. mengutip secara acak istilah, kata-kata dan/atau kalimat, data dan/ata informasi dari suatu sumber tanpa menyatakan sumber secara memadai;

c. menggunakan sumber gagasan, pendapat, pandangan, atau teo tanpa menyatakan sumber secara memadai;

d.merumuskan dengan kata-kata dan/atau kalimat sendiri dari sumber kate kata dan/atau kalimat, gagasan, pendapat, pandangan, atau teori tanp menyatakan sumber secara memadai; $(\ll<$ parafrase tanp penyebutan sumber)

e.menyerahkan suatu karya ilmiah yang dihasilkan dan/atau tela dipublikasikan oleh pihak lain sebagai karya ilmiahnya tanpa menyataka sumber secara memadai. ( $<<$ merubah nama author atau ghos author) 


\section{SUMBER}

- karya dan/atau karya ilmiah yang dibuat, diterbitkan, dipresentasikan, atau dimuat dalan bentuk tertulis baik cetak mapun elektronik.

- yang dimaksud dengan yang dibuat dapat berupa:

l.komposisi misik;

2.perangkat lunak komputer;

3.fotografi;

4.lukisan;

5.sketsa;

6.patung; atau

7.karya dan atau karya ilmiah sejenis yang tidak termasu kategori angka I s.d 6. 
dimaksud dengan diterbitkan menurut PERMENDIKNAS I7/20I0 berupa :

buku yang dicetak dan diedarkan oleh penerbit atau perguruan tinggi; artikel yang dimuat dalam berkala ilmiah, majalah, atau surat kabar; kertas kerja atau makalah profesional dari organisasi tertentu; isi laman elektronik; atau hasil karya dan/atau karya ilmiah yang tidak termasuk pada angka I s.d 4 dimaksud dengan dipresentasikan PERMENDIKNAS I7/20I0 dapat be

presentasi di depan khalayak umum atau terbatas;

presentasi melalui radio/televisi/video/cakram padat/ cakram video atau

bentuk atau cara lain sejenis yang tidak termasuk pada angka I dan 2 . 


\section{Jenis Plagiasi (COPE)}

- Auto Plagiarism/Self Plagiarism

- Plagiarism 
to Plagiarism/Redundant/duplicate

PPE. (20I5a). redundant publication. Retrieved October 3I , 20I6, from

p://publicationethics.org/files/redundant publication A_0.pdf

- Major overlap/redundancy (i.e. based on same dataset with identical findings and/or evidence that authors have sought to hide redundancy, e.g. by changing title author order or not referring to previous papers)

- Minor overlap ("salami publishing" with some elemen redundancy) or legitimate repetition or re-analysis (e. sub-group/extended follow-up/ repeated methods) 
PE. (20I5b). Suspected plagiarism in a submitted manuscript. Retrieved October 2016, from http://publicationethics.org/files/Suspected plagiarism in a submitted nuscript \%281\%29.pdf

- Clear plagiarism (unattributed use of large portions o text and/or data, presented as if they were by the plagiarist)

- Minor copying of short phrases only (e.g. in discussio research paper from non-native language speaker) $\mathrm{Nc}$ misattribution of data 


\section{Latar Belakang}

Perusahaan yang memproduksi barang atau jasa untuk memajukan usahanya menggunakan banyak strategi salah satunya dengan menggunakan merek. Merek digunakan untuk memberikan identitas terhadap barang dagangan atau produksi satu perusahaan atau jasa dengan barang atau produksi perusahaan atau jasa lain yang sejenis. Tidak dapat dibayangkan apabila suatu produk barang atau jasa dipasarkan tanpa menggunakan merek. Tentu konsumen sulit untuk

membedakan barang atau jasa dari pruduk suatu badan usaha yang satu dengan badan usaha yang lain, disamping itu konsumen juga akan kesulitan untuk memperoleh produk tersebut di pasaran, kecuali diperoleh melalui pembelian langsung di tempat produksinya atau dijajakan langsung oleh produsen kepada konsumen. Karenanya merek merupakan tanda pengenal asal barang dan jasa sekaligus mempunyai fungsi menghubungkan barang dan jasa yang bersangkutan dengan produsennya. Hal itu menggambarkan jaminan kepribadian (individuality), dan reputasi barang dan jasa hasil usahanya tersebut sewaktu diperdagangkan.

Merek dapat pula menjadi asset perusahaan apabila produk barang atau jasa yang dihasilkan dengan menggunakan merek tersebut berhasil menjadi barang atau jasa yang banyak digunakan oleh masyarakat. Maka dari itu merek yang bersangkutan akan menjadi "kata kunci" bagi masyarakat yang akan membeli suatu barang atau jasa.'

Merek merupakan satu-satunya cara untuk menciptakan dan mempertahankan goodwill di mata konsumen di pasaran luar negeri. Merek merupakan simbol bagi pihak pedagang untuk memperluas dan mempertahankan pasarnya di luar negeri. Goodwill dari suatu produk barang

\section{toh report mahasiswa hampir $100 \%$ plagiat !!}

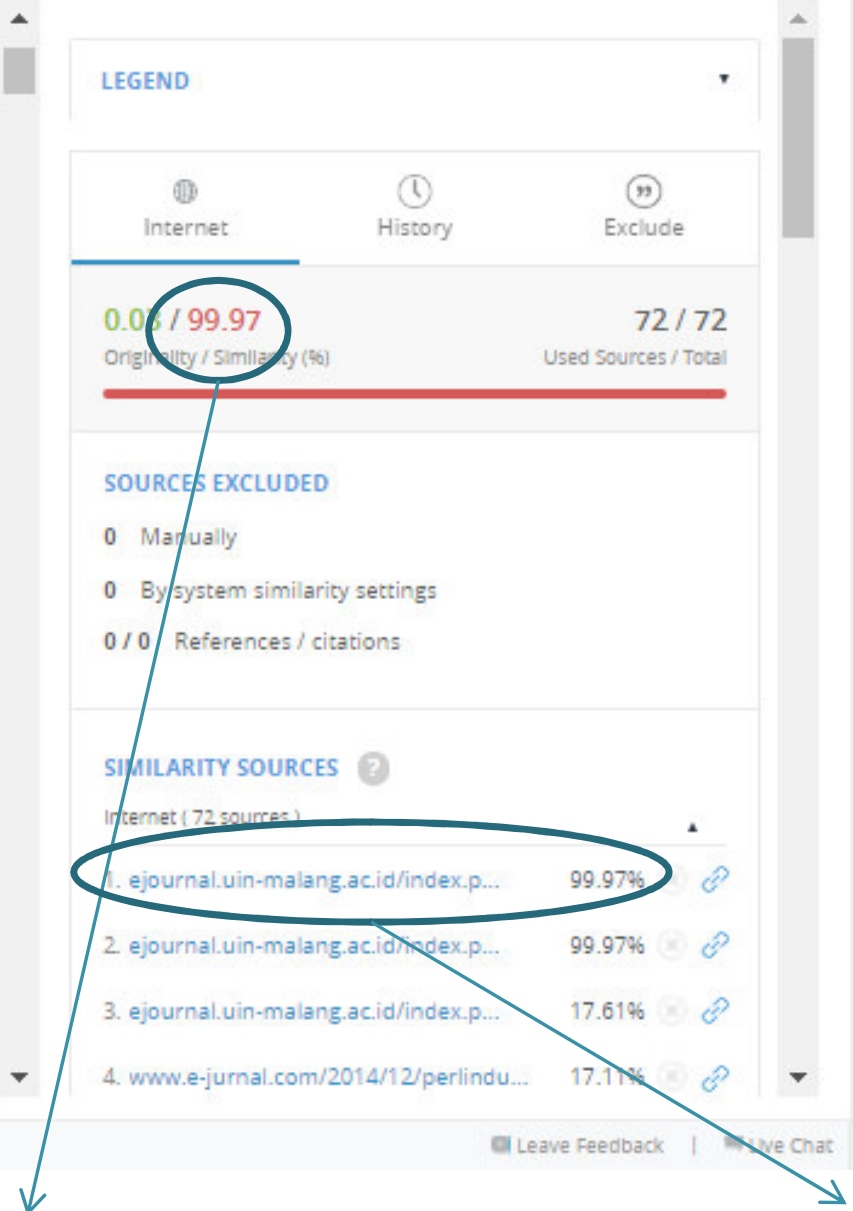

\section{Prosentase plagiat}

Mochammad Tanzil Multazam, M.Kn Sumber yang paling bany
contek dan prosentasen 


\section{Contoh report mahasiswa cuman 7\% Mirip (terkait bunyi pasal UU)}

C $\Omega$ https://unplag.com/library/viewer/report/84124

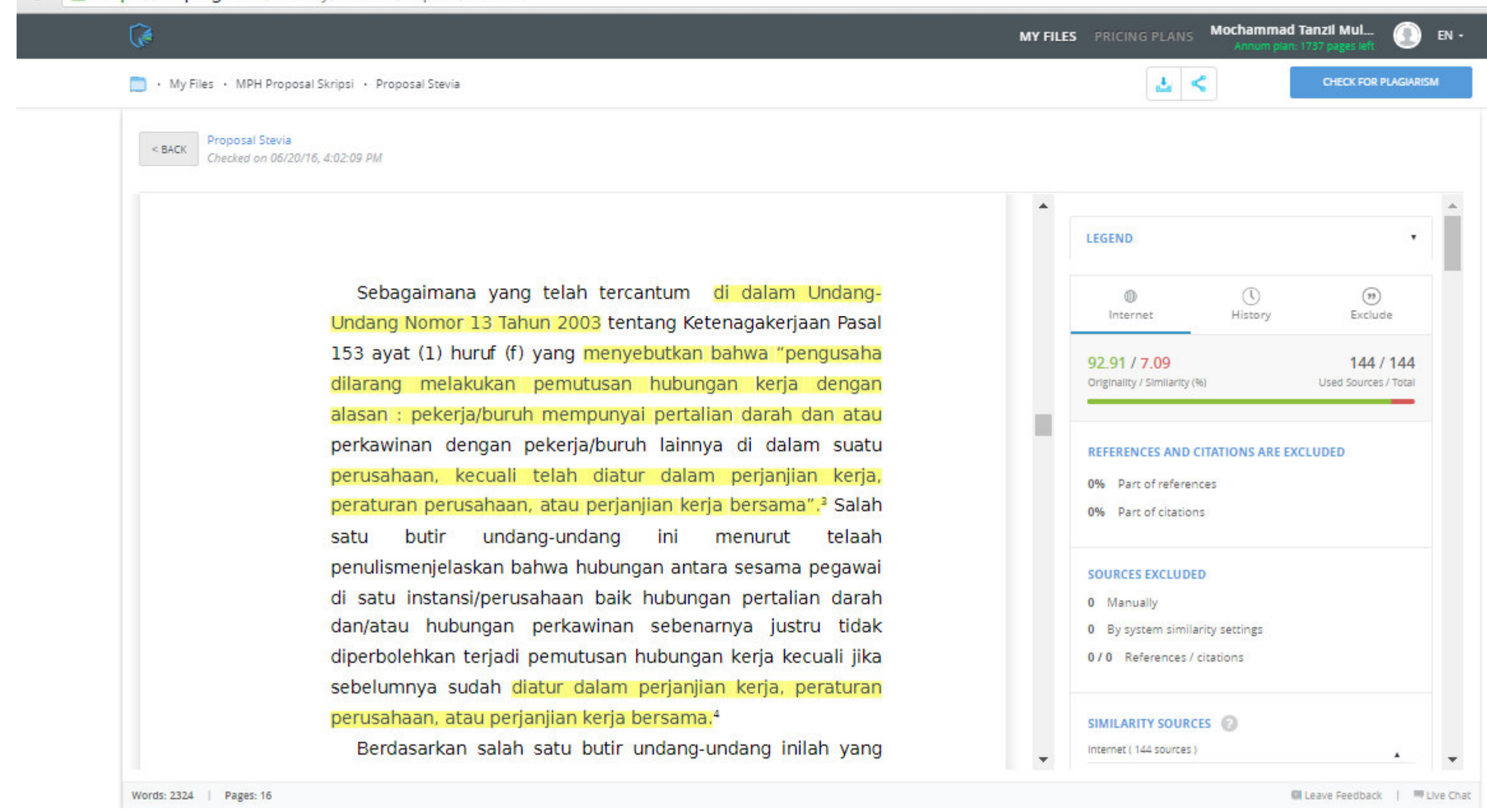


nanggulangan Plagiasi

Vays to Avoid Plagiarism in Research Papers. (2016). Retrieved October 2016, from http://en.writecheck.com/ways-to-avoid-plagiarism/

- Paraphrase

- Cite

- Quoting

- Citing Quotes

- Citing Your Own Material

- Referencing 


\section{Contoh Paraphrase}

(Paraphrase:Write It in Your Own Words. (2016). Retrieved October 31 , 2016, from https://owl.english.purdue.edu/owl/resource/6 I9/I/)

The original passage:

- Students frequently overuse direct quotation in taking notes, an a result they overuse quotations in the final [research] paper. Probably only about $10 \%$ of your final manuscript should appea directly quoted matter. Therefore, you should strive to limit the amount of exact transcribing of source materials while taking $n$ Lester, James D.Writing Research Papers. 2nd ed. (1976): 46-47.

\section{A plagiarized version:}

- Students often use too many direct quotations when they take notes, resulting in too many of them in the final research paper. fact, probably only about 10\% of the final copy should consist o directly quoted material. So it is important to limit the amount source material copied while taking notes. 


\section{Contoh Paraphrase}

(Paraphrase:Write It in Your Own Words. (2016). Retrieved October

3 I, 20 I6, from https://owl.english.purdue.edu/owl/resource/6 /9/I/)

\section{An acceptable summary:}

- Students should take just a few notes in direct quotat from sources to help minimize the amount of quoted material in a research paper (Lester 46-47).

\section{A legitimate paraphrase:}

- In research papers students often quote excessively, failing to keep quoted material down to a desirable level. Since the problem usually originates during note taking, it is essential to minimize the mate recorded verbatim (Lester 46-47). 
I. Mungkinkah 20 atau 30 tahun kedepan nati akan terw Barangkali, ini memang mimpi di siang bolong! Sama dengan $r$ besarnya PSSI merencanakan menggelar Piala Dunia 202 Indonesia. Wah, tentu ini mimpi besar. Tetapi apakah lembagc yang sudah berumur 28 tahun dan baru 8 tahun sebagai PTN bermimpi ke mana arah ke depan.

2. Mungkinkah di tahun 2025 nanti? Barangkali, ini memang mimpi di bolong! Sama dengan mimpi besarnya PSSI merencanakan meng Piala Dunia 2022 di Indonesia. Wah, tentu ini mimpi besar.Tetapi bukankah Instansi kita sudah berumur 28 tahun dan perlu ber "mimpi" ke mana arah Instansi ini akan dibawa ke depan. 


\section{Points}

I. Paraphrase $\neq$ summarize

2. Never copy more than two words in a row, use quotation if you do that.

3. Use proper citation. 


\section{Tips Menghindari Plagiasi}

How to Avoid Plagiarism. (2016). Retrieved October 31, 2016, from

http://isites.harvard.edu/icb/icb.do?keyword=k70847\&pageid=icb.page342057

- Keep track of your sources; print electronic sources (Use reference manager, e.g. Mendeley)

- Keep sources in correct context

- Plan ahead (save your time and use current research as source, find on DOAJ, portalgaruda.org, or other indexer)

- Don't cut and paste: File and label your sources

- Keep your own writing and your sources separate

- Keep your notes and your draft separate

- Paraphrase carefully in your notes; acknowledge your sources explicitly wh paraphrasing

- Avoid reading a classmate's paper for inspiration.

- Don't save your citations for later. (always cite immediately after you wrot

- Quote your sources properly

- Keep a source trail . (keep your source, even after you finish your work) 


\section{Mendeley}

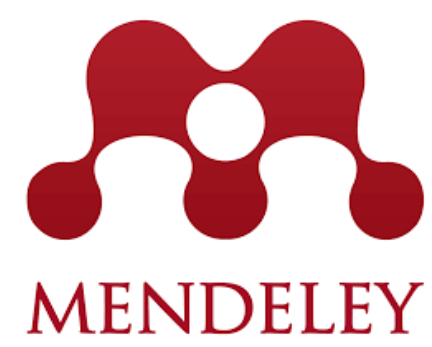

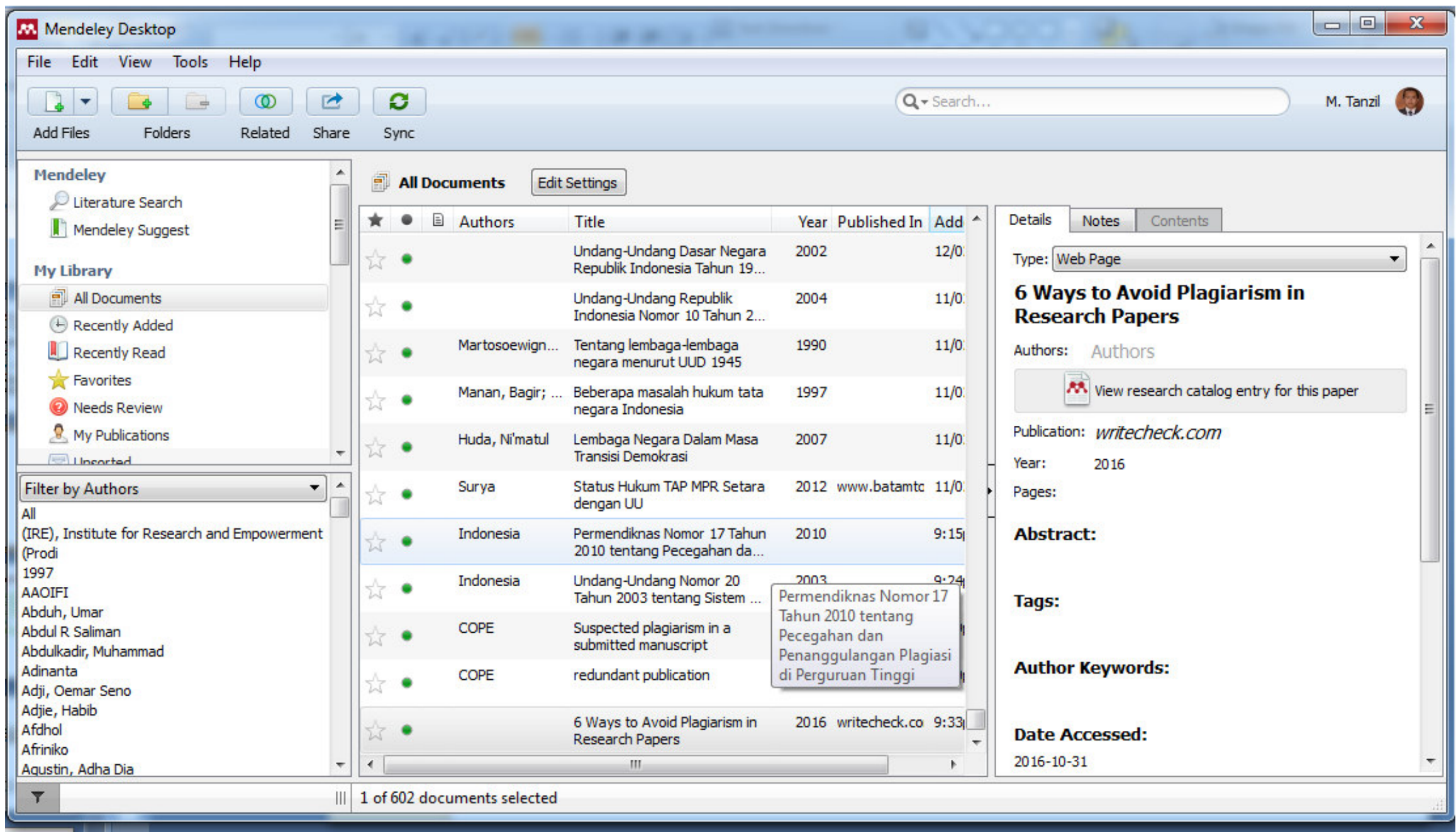

Mochammad Tanzil Multazam, M.Kn. 


\section{Indexing and Abstract Service, e.g. DOAJ and}

Igaruda.org

C Q doaj.org

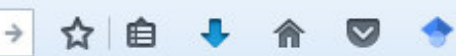

Home

Search

Journal/Book

Title

$\checkmark$

Search Document

\section{Indonesian Publication Index}

The Indonesian Publication Index (IPI) is designed for browsing, indexing, abstracting, monitoring and improving the standard of scholarly publications in Indonesia. Currently, there are over 3000 Indonesian journals for inclusion in the IPI database. The contents are very important to be made visible globally, so that Indonesian academics and researchers can be identified his/her expertise, areas of possible collaboration, stimulate use and citations. The establishment of Indonesian Publication Index (formerly Portal Garuda Indonesian Publication Index) initiated by Institute of Advanced Engineering

and Science Indonesia Section (IAES) Indonesia Section.

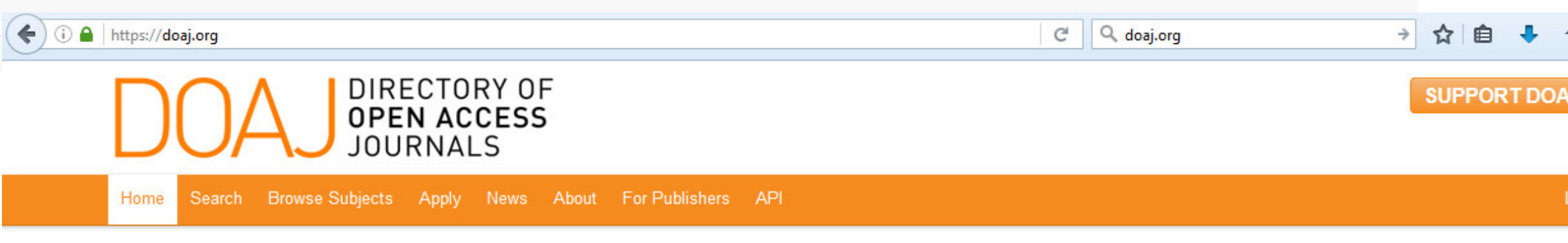

JOURNALS

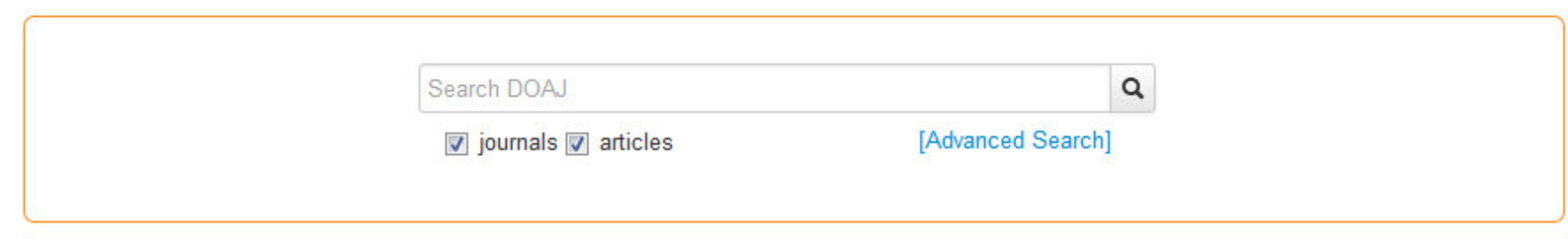

Directory of Open Access Journals (DOAJ)

9,159 Journals

6,406 searchable at Article level

128 Countries

$2,323,986$ Articles

Mon Access Information 


\section{Free Plagiarism Scan (Limited Words)}

- http://www.plagscan.com/plagiarism-check/

- http://smallseotools.com/plagiarism-checker/

- http://solidseotools.com/plagiarism-checker\&article

- https://www.plagiarismsoftware.net/

- https://unplag.com/free-plagiarism-checker/ 


\section{Sanksi Plagiarisme}

\section{UU 20/2003 Pasal 70}

- Lulusan yang karya ilmiah yang digunakannya untuk mendapatkan gelar akademik, profesi, atau vokasi sebagaimana dimaksud dalam Pasal 25 Ayat (2) terbukti merupakan jiplakan dipidana dengan pidana penjara paling lama dua tahun dan/atau pidana denda paling banyak $R p 200.000 .000,00$ (dua ratus juta rupiah).

Peraturan Menteri Nomor 17 Tahun 2010

sanksi:

- Teguran

- Peringatan tertulis

- Penundaan pemberian sebagian hak mahasiswa

- Pembatalan nilai

- Pemberhentian dengan hormat dari status sebagai mahasiswa

- Pemberhentian tidak dengan hormat dari status sebagai mahasiswa

- Pembatalan ijazah apabila telah lulus dari proses pendidikan. 


\section{References}

- 6Ways to Avoid Plagiarism in Research Papers. (2016). Retrieved October 31, 2016, from http://en.writecheck.com/ways-to-avoid-plagiarism/

- COPE. (20I5a). redundant publication. Retrieved October 3I, 2016, from http://publicationethics.org/files/redundant publication A_0.pdf

- COPE. (20I5b). Suspected plagiarism in a submitted manuscript. Retrieved October 3I, 2016, fr http://publicationethics.org/files/Suspected plagiarism in a submitted manuscript \%281\%29.pdf

- How to Avoid Plagiarism. (2016). Retrieved October 31, 2016, from http://isites.harvard.edu/icb/icb.do?keyword=k70847\&pageid=icb.page342057

- Indonesia. Undang-Undang Nomor 20 Tahun 2003 tentang Sistem Pendidikan Nasional (2003).

- Indonesia. Permendiknas Nomor 17 Tahun 2010 tentang Pecegahan dan Penanggulangan Plagiasi Perguruan Tinggi (2010).

- Paraphrase:Write It in Your Own Words. (2016). Retrieved October 31, 2016, from https://owl.english.purdue.edu/owl/resource/619/1/

- Preventing plagiarism when writing. (2016). Retrieved October 3I, 2016, from http://www.plagiarism.org/plagiarism-10I/prevention/

- Sosialisasi SE Dikti No 153/20I2 Serta PENCEGAHAN \& PENANGGULANGAN PLAGIASI D PERGURUAN TINGGI Berdasarkan (PERMENDIKNAS NOMOR I7TAHUN 20I0. (n.d.).

- http://Unplag.com 